\title{
Congenital Factor V Deficiency: Moroccans Cases
}

\author{
Oukkache Bouchra Louai ${ }^{1}$, Marielle Igala ${ }^{2 *}$ \\ ${ }^{1}$ Teaching Hospital CHI Ibn Rochd - Hematology Laboratory, Casablanca 20200, Morocco; ${ }^{2}$ Ibn Rochd Teaching Hospital - \\ Hematology Laboraty, Quartier des Hopitaux, Casablanca 20200, Morocco
}

\author{
Citation: Louai $\mathrm{OB}$, Igala M. Congenital Factor \\ $\checkmark$ Deficiency: Moroccans Cases. Maced J Med \\ Sci. $2013 \quad$ Sep 15; 6(3):278-280 \\ http://dx doi.org/10.3889/MJMS.1857- \\ 5773.2013.0293. \\ Key words: Factor V; Coagulation; Deficit; \\ Congenital; Coagulopathy. \\ "Correspondence: Dr. Marielle Igala. Ibn Rochd \\ Teaching Hospital, Hematology Laboraty, \\ Quartier des Hopitaux, Casablanca 20200 , \\ Morocco. E-Mail: marieligalase@yahoo.fr \\ Received: 05-Jan-2013; Revised: 01-Apr- \\ 2013; Accepted: 03-May-2013; Online first: \\ 18-Jun-2013 \\ Copyright: $\odot 2013$ Louai OB. This is an open- \\ access article distributed under the terms of \\ the Creative Commons Attribution License, \\ which permits unrestricted use, distribution, \\ and reproduction in any medium, provided the \\ original author and source are credited. \\ Competing Interests: The authors have \\ declared that no competing interests exist.
}

\begin{abstract}
Background and Objective: The congenital factor $V$ deficiency, known as Owren's disease or parahemophilia is a rare autosomic recessive haemorrhagic disease of coagulation, identified for the first time in Norway in 1943. In Morocco, there is no national registry including cases of congenital coagulopathy. This study highlights the rarity of inherited factor $\mathrm{V}$ deficiency deficiency and the importance of coagulation testing in the diagnosis of condition.
\end{abstract}

Patients and Methods: We report twelve cases of factor $V$ deficiency at our institution.

Results: Of the 12 cases, seven were followed at the haematology department; the remaining five were discovered during a family survey. The average age of our patients is 16 years old [ $1-40$ years], with a female dominance (Sex ratio F/M: 2). Parental consanguinity was found in three patients, bleeding family history were found in 5 patients. The concept of bleeding was found in 6 of 7 cases of patients followed, in 1 patient's case the discovery was fortuitous.

Conclusion: Inherited factor $V$ deficiency is a rare inherited disorder. The diagnosis is mainly based on coagulation tests; however, the bleeding tendency may be severe and occurs early in life with immeasurable factor II levels.

\section{Introduction}

Factor V, known as Owren's disease or parahemophilia is a very rare inherited haemorrhagic disease of coagulation with an autosomic recessive transmission, identified for the first time in Norway in 1943 [1]. About one person in a million may be affected by this deficiency, it is asymptomatic among the heterozygous, and manifests itself among the homozygote by some mucocutaneous bleeding of variable intensity depending on families.

We conducted a retrospective analysis of all cases with factor $V$ deficiency that were seen and followed up within a 21- year period at the University Hospital of Casablanca, a large Moroccan city with more than 3 million habitants.

\section{Patients and Methods}

Between January 1991 - December 2012 (no new case was noted), the medical records of patients with congenital factor $V$ deficiency were followed up at University Hospital Center 'Ibn Rochd' in Casablanca and were carefully reviewed for clinical and laboratory features. The Ibn Rochd Center is one of the biggest university hospitals in Morocco and receives approximately 98000 patients per year.

We have gathered studied the different data (epidemiological, clinical, biological and therapeutic) and we have conducted a family survey in search of similar cases. The biological diagnosis of the deficit is based on an assessment of haemostasis with the exploration of prothrombin time (PT) test in the presence of neoplastin (Diagnostica stago type), 
partial thromboplastin time with activators (aPTT) test performed in the presence of cephalin (Organo type) and a specific measure for factor $\mathrm{V}$ by chronometric method with a deficient substrat in factor $V$ and in the presence of thromboplastin [normal range of factor $\mathrm{V}$ : 70-100\%]

The severity of the factor $V$ deficiency is classified according to the level of the factor $\mathrm{V}$ deficiency. The deficit is severe if the factor $V$ is $\leq 1 \%$, moderate if the factor $V$ is $<5 \%$ and minor if the factor $\mathrm{V}$ is $\mathrm{V} \geq 5 \%$.

Factor VIII is measured in all patients to eliminate a combined deficit.

\section{Results}

Twelve patients were included with a factor $\mathrm{V}$ deficit. Seven patients were followed for a hemorrhagic syndrome and five were diagnosed as part family survey. The average age of the patients was 16 with extremes of 1 to 40 years. The sex ratio was 2 with female predominance. Parental consanguinity of the first degree was found in three patients.

Table 1: The presenting signs of patients in the series.

\begin{tabular}{|c|c|c|c|}
\hline Patients & $\begin{array}{c}\text { Age } \\
\text { (years) }\end{array}$ & Sex & Telltale signes \\
\hline Case 1 & 39 & $\mathrm{~F}$ & $\begin{array}{l}\text { Menorrhagia } \\
\text { Purpuric lesions of the lower limbs }\end{array}$ \\
\hline Case 2 & 18 & $\mathrm{~F}$ & $\begin{array}{l}\text { Intraoperative bleeding following surgery } \\
\text { for aneurysmal cyst of the mandible }\end{array}$ \\
\hline Case 3 & 17 & $\mathrm{~F}$ & $\begin{array}{l}\text { Menorrhagia } \\
\text { Epistaxis }\end{array}$ \\
\hline Case 4 & 14 & $\mathrm{~F}$ & $\begin{array}{l}\text { Menorrhagia } \\
\text { Bleeding after tooth ectraction }\end{array}$ \\
\hline Case 5 & 4 & $\mathrm{~F}$ & Preoperative review \\
\hline Case 6 & 15 & M & $\begin{array}{l}\text { Hematoma of the forearm and hemarthrosis } \\
\text { Epistaxis }\end{array}$ \\
\hline Case 7 & 1 & M & Circumcision bleeding \\
\hline Case 8 & 4 & $\mathrm{~F}$ & Family survey \\
\hline Case 9 & 10 & $\mathrm{~F}$ & Family survey \\
\hline Case 10 & 7 & $\mathrm{~F}$ & Family survey \\
\hline Case 11 & 30 & M & Family survey (history of epistaxis) \\
\hline Case 12 & 29 & M & Family survey \\
\hline
\end{tabular}

In 7 patients followed in our unit; presenting signs of deficiency were: menorrhagia in 3 cases, epistaxis in 2 cases, purpuric lesions of lower limbs in 1 patient, circumcision bleeding in 1 case, a hematoma with hemarthrosis in 1 case, bleeding after tooth extraction in 1 case, intra-operative bleeding in 1 case and a chance discovery during a preoperative review in 1 case (Table 1 ).

Of the five patient discovered in the family survey, one patient has a history of epistaxis. All patients had abnormal coagulation evaluation with lengthening of PT and aPTT. The activity of factor $\mathrm{V}$ was greater than or equal to $5 \%$ in 8 patients, less than $5 \%$ in 4 patients. No associated deficit has been founded (Table 2).
Table 2: Patients haemostasis and factor V activity.

\begin{tabular}{cccc}
\hline Patients & PT (70-100\%) & $\begin{array}{c}\text { aPTT } \\
(\mathbf{3 0} \pm \mathbf{5} \mathbf{~ s e c})\end{array}$ & $\begin{array}{c}\text { Facteur activity V } \\
\mathbf{( 7 0 - 1 4 0 \% )}\end{array}$ \\
\hline Case 1 & $\mathbf{3 2}$ & 91 & $\mathbf{4}$ \\
Case 2 & $\mathbf{5 0}$ & 51 & $\mathbf{5 0}$ \\
Case 3 & $\mathbf{2 4}$ & 60 & $\mathbf{5 0}$ \\
Case 4 & $\mathbf{2 7}$ & 40 & $\mathbf{5}$ \\
Case 5 & $\mathbf{1 7}$ & 91 & $\mathbf{4}$ \\
Case 6 & $\mathbf{4 0}$ & 90 & $\mathbf{2}$ \\
Case 7 & $\mathbf{4 0}$ & 84 & $\mathbf{2}$ \\
\hline
\end{tabular}

\section{Discussion}

Factor $\mathrm{V}$ or proaccelerin is blood clotting protein that acts as a cofactor, accelerating the conversion of prothrombin into thrombin. It belongs to the common pathology, and it is at the centre of regulatory mechanisms of coagulation, allowing the reaction at the site to occur at the site of vascular injury.

The gene responsible for synthesis of factor $\mathrm{V}$ is located on the $1 \mathrm{q} 23$ locus. These are mutations at this locus that are responsible of the deficit. They affect the two chromosome pairs in the homozygous symptomatic forms [2].

The congenital deficiency of Factor $\mathrm{V}$ is rare, affecting $1 / 1000000$ individuals in the general population. However, its prevalence may be underestimated because mild cases are often overlooked [1, 3, 4]. This deficiency is due to an autonomic recessive transmission, it is more common in countries where consanguineous marriages are common, which is the case in our country. Until now only 200 cases have been reported $[3,5]$.

Congenital factor $\mathrm{V}$ deficiency type $\mathrm{I}$ is defined by a reduction FV activity and antigen. For type II, the deficit is qualitative and is characterized by low of stability of activated factor $\mathrm{V}$ with normal antigen level $[6,7]$.

Biological factor $\mathrm{V}$ deficiency is characterized by clinical phenotype and genotype heterogeneity [1, 3].

Factor $\mathrm{V}$ deficiency is usually asymptomatic in heterozygote or homozygote patient, but in some patients it is manifested by mucosal or cutaneous bleeding of variable intensity [3, 9].

A large Study of 35 Iranian patients reported mucocutaneous bleeding in $57 \%$, bleeding of the oral cavity in $57 \%$, heavy or prolonged menstrual bleeding in $50 \%$, post-traumatic bleeding and peri- operating in $43 \%$ of muscle hematomas in $29 \%$, hemarthrosis in $26 \%$.

Intracranial or gastrointestinal tract hemorrhages are rare $(6 \%)$ and are limited to patients with undetectable $\mathrm{FV}$; they occur mainly in the perinatal period $[3,8]$.

The results of our study are consistent with those reported, despite a very small number of 
patients in our series, with mucosal bleeding found in 2 of 7 patients and menorrhagia in 3 out of 6 female patients.

In most cases of severe FV deficiency hemorrhagic signs appear at birth or in infancy, but some remain virtually asymptomatic until late in life and may be discovered incidentally after a routine coagulation evaluation [4, 9]. Heterozygotes are usually asymptomatic or have minor bleeding.

The biological diagnosis is suggested in a prolonged $\mathrm{PT}$ and aPTT. It is confirmed by the analytical determination of factors II, VII, X and V, confirming the isolated deficiency of clotting activity of factor $\mathrm{V}$. There is no correlation between FV and intensity of clinical signs, in fact there is no parallelism between the degree of deficit and the severity or frequency of symptoms [3, 7].

The treatment or prevention of first-line intraoperative haemorrhage involves transfusion of fresh frozen plasma (FFP) because there is no specific FV concentrate $[3,6,7]$.

The aim of treatment by FFP is maintain of the FV level above $20 \%$. The half-life of $F V$ is $12-36 \mathrm{~h}$, a daily transfusion of $15-20 \mathrm{ml} / \mathrm{kg}$ FFP is sufficient to obtain the therapeutic level. The frequency and dose must be adjusted on a case by case basis [3, 10]. For less severe mucocutaneous bleeding, the use of an antifibrinolytic such as aminocaproic acid may be sufficient.

In conclusion, Factor $\mathrm{V}$ deficiency is a rare bleeding disorder affecting both men and women, and it may cause in some cases very severe bleeding. Its diagnosis is easily made by standard coagulation of evaluation of PT, aPTT and factor $\mathrm{V}$ activity level. Early diagnosis is essential for adequate replacement therapy to be instituted if necessary. Given the small numbers of patients with factor $V$ deficiency, is essential to continue collaborative efforts with international registries to expand our knowledge of this and other rare coagulation disorders.

\section{References}

1. Stormorken $\mathrm{H}$. The discovery of factor $\mathrm{V}$ : a tricky clotting factor. J Thromb Haemost. 2003;1(2):206-13.

2. Cripe LD, Moore KD, Kane WH. Structure of the gene for human coagulation factor V. Biochemistry. 1992; 31: 3777-85.

3. Lak M, Sharifian R, Peyvandi F, Mannucci PM. Symptoms of inherited factor $\mathrm{V}$ deficiency in 35 Iranian patients. $\mathrm{Br} \mathrm{J}$ Haematol. 1998; 103: 1067-9.

4. Duckers C, Simioni P, Rosing J, Castoldi E. Advances in understanding the bleeding diasthesis in factor $\mathrm{V}$ deficiency. $\mathrm{Br} \mathrm{J}$ Haematol. 2009;146(1):17-26.

5. Asselta R, Peyvandi F. Factor $V$ deficiency. Semin Thromb hemost. 2009; 35(4): 382-9.

6. Asselta R, Tenchini ML, Duga S. Inherited defects of coagulation factor V: the hemorrhagic side. J Thromb Haemost. 2006; 4: 26-34.

7. Mannucci PM, Duga S, Peyvandi F. Recessively inherited coagulation disorders. Blood. 2004;104(5)1243-51.

8. Ellestad SC, Zimmerman SA, Thornburg C, Mitchell TE, Swamy GK, James AH. Severe factor $V$ deficiency presenting with intracranial haemorrhage during gestation. Haemophilia. 2007;13: 432-34.

9. Alcantara M, Ducastelle S, Rugeri L, Dargaud Y. Acquired factor $\checkmark$ deficiency: A rare bleeding disorder with variable clinical presentations. Rev Med Intern. 2010;3976.

10. Huang JN, Koerper MA.Factor V deficiency: a concise review. Haemophilia. 2008;14:1164-9. 